\title{
Caracterização morfocultural, biossíntese de autoindutor e formação de biofilme por rizobactérias de hortaliças
}

\author{
Rachel Pinton ${ }^{(1)}$, Anelise Dias ${ }^{(1)}$, Terezinha Ferreira Xavier ${ }^{(2)}$, Luc Felicianus Marie Rouws ${ }^{(3)}$, \\ Gustavo Ribeiro Xavier ${ }^{(3)}$, Norma Gouvêa Rumjanek ${ }^{(3)}$ e Raul de Lucena Duarte Ribeiro(1)
}

\begin{abstract}
(1)Universidade Federal Rural do Rio de Janeiro, Rodovia BR 465, km 07, CEP 23890-000 Seropédica, RJ. E-mail: rachelpinton@yahoo.com.br, anelise.dias@gmail.com, ribeiro.lucena@gmail.com (2)Universidade Federal Rural de Pernambuco, Rua Dom Manoel de Medeiros, s/no, Dois Irmãos, CEP 52171-900 Recife, PE. E-mail: teferxa@hotmail.com (3)Embrapa Agrobiologia, Rodovia BR 465, Km 07, CEP 23890-000 Seropédica, RJ. E-mail: lucrouws@hotmail.com, gustavo@cnpab.embrapa.br, norma@cnpab.embrapa.br
\end{abstract}

Resumo - $\mathrm{O}$ objetivo deste trabalho foi caracterizar e agrupar rizobactérias, isoladas de hortaliças, quanto à morfologia cultural, riqueza e diversidade e avaliar a biossíntese de autoindutores $\mathrm{N}$-acil lactonas homoserinas (ALH) e a capacidade de formação de biofilmes. Sete estirpes também foram avaliadas quanto ao potencial de promoção de crescimento de Brassica oleraceae var. acephala em casa de vegetação. Para verificar a produção de ALH, foram realizados ensaios com Agrobacterium tumefaciens estirpe NT1 como sistema repórter. A formação de biofilme foi avaliada pelo cultivo do isolado em meio líquido. A promoção do crescimento foi avaliada após inoculação das estirpes em plantas de couve-de-folha pela determinação da produção de massa de matérias fresca e seca. A maior diversidade morfocultural foi encontrada entre as estirpes isoladas de couve-de-folha. De um total de 112 estirpes testadas, 13\% foram positivas quanto à produção de ALH; de 91 estirpes, $96 \%$ foram capazes de formar biofilmes; e de 79 estirpes, 11\% foram positivas para ambas as características. Foram observadas diferenças significativas na massa de matéria seca das raízes com inoculação de $10^{9} \mathrm{UFC} \mathrm{mL}^{-1}$ da estirpe R142, que incrementou em 55\% a massa de matéria seca das raízes de couve, em relação ao controle. Não há relação entre a capacidade de formar biofilme e a detecção de ALH produzidos pelas rizobactérias avaliadas.

Termos para indexação: autoindutores, promoção de crescimento, rizobactérias.

\section{Morphocultural characterization, autoinducer biosynthesis and biofilm formation in rhizobacteria isolated from vegetable crops}

\begin{abstract}
The objective of this work was to characterize and group rhizobacteria isolated from vegetable crops for culture morphology, richness and diversity, and to evaluate the biosynthesis of $\mathrm{N}$-acyl homoserine lactone (AHL) autoinducers and the capacity to form biofilms. Seven strains were also assessed for their potential to promote plant growth of Brassica oleraceae var. acephala in greenhouse. To test the production of AHL, the indicator strain Agrobacterium tumefaciens NT1 was used. The formation of biofilms was evaluated by cultivating the isolates in liquid medium. Growth promotion was evaluated after the inoculation of the strains in kale plants and through determination of the fresh and dry mass production. The largest morphocultural diversity was found among the strains isolated from kale. From a total of 112 tested strains, 13\% were positive for AHL production, among 91 strains, $96 \%$ were capable to form biofilms, and among 79 strains, $11 \%$ were positive for both characteristics. Significant differences were observed in root dry mass of plants inoculated with $10^{9} \mathrm{UFC} \mathrm{mL}^{-1}$ of strain R142 that increased in $55 \%$ the root dry mass in comparison to the control. There is no relationship between the capacity to form biofilms and the detection of the AHL produced by the evaluated rhizobacteria.
\end{abstract}

Index terms: autoinducers, growth promotion, rhizobacteria.

\section{Introdução}

A colonização radicular por rizobactérias fluorescentes do gênero Pseudomonas spp. induz o aumento da produtividade de diversas culturas, em consequência da biossíntese de sideróforos, reguladores de crescimento, antibióticos e hidrolases (Cook, 2007; Compant et al., 2010). A produção de metabólitos secundários e a formação de biofilme podem ser reguladas pelo mecanismo de monitoramento populacional ou "quorum sensing” (QS) (Choudhary et al., 2009). Por meio desse sistema, seres unicelulares produzem substâncias sinalizadoras, denominadas autoindutores, que se difundem livremente através da membrana celular para o meio. A partir de determinada concentração, estas substâncias desencadeiam alterações na expressão de genes específicos. Desta forma, o QS permite uma

Pesq. agropec. bras., Brasília, v.45, n.3, p.284-293, mar. 2010 
resposta coordenada do organismo em função da densidade populacional (Rumjanek et al., 2004).

Uma crescente lista de sinais autoindutores vem sendo reconhecida, da qual se destacam $\mathrm{N}$-acil lactonas homoserinas (ALH), peptídeos, furanosil di-ester, também conhecido como autoindutor-2, gama-butirolactonas e quinolonas (Camilli \& Bassler, 2006; Decho et al., 2010). As bactérias Gram-negativas produzem, em geral, ALH, e a habilidade na comunicação intercelular tem sido demonstrada em diversas espécies do gênero Pseudomonas (Juhas et al., 2005; Veselova et al., 2010). Neste grupo bacteriano, o sistema QS está envolvido com a competência rizosférica para regular a mobilidade, tolerância a estresses, transferência horizontal de genes, surfactantes, antibióticos, enzimas extracelulares e formação de biofilmes (Bodman, 2003; Decho et al., 2010).

Os biofilmes bacterianos são agregados multicelulares aderidos aum substrato biótico ounão, inseridos emmatrizes poliméricas, que são geralmente associadas a mecanismos deQS eque permitem o acúmulo de autoindutores (Danhorn \& Fuqua, 2007). Estas matrizes conectam as células e consistem basicamente de polissacarídeos extracelulares e podem conter DNA e proteínas (Costerton et al., 1999). A formação de biofilmes protege a população bacteriana quando inoculada no solo e nas sementes e favorece a manutenção de uma densidade populacional para que se iniciem interações benéficas ou deletérias entre a planta e a bactéria (Danhorn \& Fuqua, 2007).

Frequentemente, bactérias que formam biofilmes produzem ALHs. Estas duas características podem ser consideradas como parâmetros adicionais à caracterização morfocultural e aos testes de eficiência para a seleção de bactérias promotoras do crescimento vegetal (Haas \& Défago, 2005).

Os objetivos deste trabalho foram caracterizar e agrupar rizobactérias isoladas de hortaliças quanto à morfologia cultural, riqueza e diversidade e avaliar a biossíntese do autoindutor $\mathrm{N}$-acil lactonas homoserinas (ALHs) e a capacidade de formação de biofilmes. Sete estirpes também foram avaliadas quanto à capacidade de promover o crescimento de Brassica oleraceae var. acephala em casa de vegetação.

\section{Material e Métodos}

A coleção de rizobactérias fluorescentes foi obtida a partir da coleta de raízes de três plantas das espécies couve-de-folha (Brassica oleracea cv. acephala), alface
(Lactuca sativa), salsa (Petroselinum sativum) e rúcula (Eruca sativa), ao final do primeiro terço do ciclo vegetativo. Essas hortaliças foram cultivadas no Sistema Integrado de Produção Agroecológica (SIPA), conduzido desde 1993, por meio de convênio de cooperação técnica entre a Empresa Brasileira de Pesquisa Agropecuária (Embrapa Agrobiologia e Embrapa Solos), a Universidade Federal Rural do Rio de Janeiro (UFRRJ) e a Empresa de Pesquisa Agropecuária do Estado do Rio de Janeiro (Pesagro-Rio/Estação Experimental de Seropédica). As raízes finas (1 a $2 \mathrm{~mm}$ ) de cada espécie foram agitadas em solução salina $(0,85 \% \mathrm{NaCl})$ por $20 \mathrm{~min}$. De cada suspensão, retirou-se uma alíquota de $8 \mathrm{~mL}$ que foi centrifugada a $15.700 \mathrm{~g}$ por $30 \mathrm{~min}$ a $4^{\circ} \mathrm{C}$. O sobrenadante foi descartado, e o precipitado foi ressuspendido em $1 \mathrm{~mL}$ de água destilada e autoclavado ( $1 \mathrm{~atm}, 120^{\circ} \mathrm{C}$ ). Apartirdessa suspensão, forampreparadas diluições seriadas até $10^{-8}$, e alíquotas de $100 \mu \mathrm{L}$ de cada diluição foram aplicadas em meio de cultura King B sólido, adicionado com os antibióticos ampicilina $\left(50 \mu \mathrm{gmL}^{-1}\right)$, cloranfenicol $\left(12,5 \mu \mathrm{gmL}^{-1}\right)$ ecicloheximida $\left(100 \mu \mathrm{g} \mathrm{mL}^{-1}\right)$. As alíquotas foram incubadas a $29^{\circ} \mathrm{C}$ por 48 horas, em triplicatas. Após esse período, as colônias obtidas foram individualmente transferidas para outras placas de King B e foram novamente incubadas $a 2^{\circ} \mathrm{C}$ por 48 horas. A massa celular que cresceu foi analisada sob luz ultravioleta, e as estirpes que emitiram fluorescência foram armazenadas em meio King B líquido com 50\% de glicerol a $-20^{\circ} \mathrm{C}$. Foram obtidos 127 isolados.

As estirpes foram caracterizadas de acordo com os seguintes parâmetros morfoculturais: tamanho ( $<1 \mathrm{~mm}$, entre 1 a $2 \mathrm{~mm}$ e $>2 \mathrm{~mm}$,), forma (circular ou oval), borda (lisa ou ondulada), aspecto (homogênea ou heterogênea), cor (amarela ou creme), transparência (translúcida ou opaca), elevação (presente ou ausente), produção de muco (baixa, média ou alta), elasticidade do muco (baixa, média ou alta), aderência ao meio de cultura (presente ou ausente) e intensidade de fluorescência (baixa, média ou alta) por metodologia adaptada de Ferreira et al. (2009). Os dados referentes à caracterização morfocultural foram submetidos a cálculos de similaridade com o coeficiente Jaccard, por meio do programa NTSYSpc versão 2.10t (Applied Biostatistics Inc., NY, EUA). Em seguida, os dados foram usados para o agrupamento dessas estirpes, a partir da planta de origem. Para a avaliação da diversidade, foram estimados índices de Shannon-Wiever, Simpson 
e Margalef, além da riqueza de grupos morfológicos associados às hortaliças (Magurran, 1988).

Para a detecção da produção de ALH utilizouse Agrobacterium tumefaciens NT1, como sistema repórter, cuja produção de ALH foi bloqueada por mutação, mas que contém o gene repórter lacZ (beta-galactosidase) ativado por ALH exógenos. Esta estirpe foi cultivada em meio de cultura TY semisólido (Beringer, 1974), na presença do indicador da atividade da beta-galactosidase, 5-bromo-4-cloro-3-indolil- $B$-D-galactopiranosídeo (X-Gal). Ao entrar em contato com uma estirpe produtora de ALH, foi observada a hidrólise do X-Gal através da coloração azul do indicador (Van Houdt et al., 2004). A partir dos grupos definidos com as características morfoculturais, foram avaliadas 112 estirpes em triplicata, com pelo menos seis estirpes de cada grupo, que foram cultivadas em meio King B sólido 24 horas antes do sistema repórter. Fragmentos de meio sólido circulares, com $0,5 \mathrm{~cm}$ de diâmetro, que continham uma colônia de rizobactéria, foram transferidos para o meio com $A$. tumefaciens repórter. $\mathrm{O}$ sistema foi incubado em estufa a $29^{\circ} \mathrm{C}$, durante 24 horas.

Para a avaliação da produção de biofilme, foram selecionadas pelo menos duas estirpes de cada grupo morfocultural, no total de 91 estirpes que foram pré-cultivadas em meio King B sólido a $29^{\circ} \mathrm{C}$ durante 24 horas e, então, cultivadas em $3 \mathrm{~mL}$ de meio King B líquido a $29^{\circ} \mathrm{C}$, durante 24 horas sob agitação. A formação de biofilme foi observada nas paredes do tubo de ensaio de vidro.

Para avaliar a capacidade de promoção do crescimento de plantas, foram selecionadas sete estirpes com características contrastantes (planta de origem, formação de biofilme e produção de $\mathrm{ALH}$ ), com duas doses de inóculo ( $10^{9}$ e $\left.10^{7} \mathrm{UFC}^{-1}\right)$. Das estirpes selecionadas, quatro foram obtidas de alface, duas de couve e uma de rúcula (R142). Duas estirpes obtidas de alface (A1101 e A161), duas obtidas de couve (C122 e C352) e uma de rúcula não produziram ALH mas formaram biofilme, enquanto outras duas estirpes obtidas de alface (A242 e A263) foram positivas para ambas as características. Para a obtenção das suspensões bacterianas, as estirpes foram cultivadas em meio King B líquido $\left(29^{\circ} \mathrm{C}, 24\right.$ horas) e centrifugadas $(15.700 \mathrm{~g}, 15 \mathrm{~min})$. O precipitado foi ressuspendido em água destilada e autoclavada (200 mL). O experimento foi conduzido em vasos com $1 \mathrm{~kg}$ de terra não autoclavada, do horizonte A de um Planossolo. A inoculação $(200 \mu \mathrm{L})$ foi realizada 10 dias após o plantio (DAP), tendo-se aplicado a suspensão sobre a região das raízes das plântulas de couve. A testemunha recebeu o mesmo volume de água destilada e autoclavada. O delineamento experimental adotado foi o de blocos ao acaso, com cinco repetições. Aos $27 \mathrm{DAP}$, foram adicionados $0,20 \mathrm{~L}$ por vaso de uma soluçãonutritivaa $10 \%$, com: $\mathrm{KCl}, 5,96 \mathrm{~g} ; \mathrm{K}_{2} \mathrm{HPO}_{4}, 2,0 \mathrm{~g}$; $\mathrm{KH}_{2} \mathrm{PO}_{4}, 4,0 \mathrm{~g} ; \mathrm{CaSO}_{4} \cdot 2 \mathrm{H}_{2} \mathrm{O}, 13,76 \mathrm{~g} ; \mathrm{MgSO}_{4} .7 \mathrm{H} 2 \mathrm{O}$, $19,72 \mathrm{~g} ; \mathrm{CuSO}_{4} .5 \mathrm{H}_{2} \mathrm{O}, 0,15 \mathrm{~g} ; \mathrm{ZnSO}_{4} .7 \mathrm{H}_{2} \mathrm{O}, 0,44 \mathrm{~g}$; $\mathrm{MnSO}_{4} \cdot 2 \mathrm{H}_{2} \mathrm{O}, 0,40 \mathrm{~g}$; $\left(\mathrm{NH}_{4}\right)_{6} \mathrm{Mo}_{7} \mathrm{O}_{24} \cdot 4 \mathrm{H}_{2} \mathrm{O}, 0,02 \mathrm{~g}$; $\mathrm{H}_{3} \mathrm{BO}_{3}, 1,43 \mathrm{~g} ; \mathrm{FeSO}_{4} .7 \mathrm{H}_{2} \mathrm{O}, 5,0 \mathrm{~g}$; ácido cítrico, $5,0 \mathrm{~g}$. Os vasos foram mantidos em casa de vegetação à temperatura média de $27^{\circ} \mathrm{C}$ e irrigados com água destilada sempre que necessário. A coleta das plantas foi realizada aos 55 DAP, e os parâmetros avaliados foram: massa de matéria fresca e seca da parte área e massa de matéria seca das raízes. As diferenças entre as médias foram comparadas pelo teste de Tukey a 5\% de probabilidade.

\section{Resultados e Discussão}

O total de 127 estirpes foi obtido das rizosferas de hortaliças (Tabela 1). Destas, 17 (13\%) foram isolados de alface, 29 (23\%) de rúcula, $33(26 \%)$ de salsa e $48(38 \%)$ de couve. As estirpes foram caracterizadas de acordo com os parâmetros morfoculturais em atributos

Tabela 1. Origem, agrupamento e diversidade de rizobactérias isoladas de hortaliças ${ }^{(1)}$.

\begin{tabular}{lcccccccc}
\hline Planta & N & G & SG & Shannon-Wiever & S-1 & Margalef & Riqueza & Simpson \\
\hline Alface & 17 & 3 & 13 & 2,05 & 12 & 4,24 & 9,75 & 0,09 \\
Rúcula & 29 & 2 & 16 & 2,05 & 15 & 4,45 & 10,26 \\
Salsa & 33 & 2 & 18 & 2,01 & 17 & 4,86 & 11,20 \\
Couve & 48 & 3 & 20 & 1,91 & 19 & 4,93 & 11,36 \\
\hline Total & 127 & 10 & 67 & - & - & - & - & 0,06 \\
\hline
\end{tabular}

(1) N, número de estirpes; G, grupo; SG, subgrupo morfocultural; índices de diversidade e riqueza (S-1). 
da colônia e do muco. Foram definidos 10 grupos, divididos em 67 subgrupos com $64 \%$ de similaridade entre si, de acordo com a rizosfera de origem.

As características morfoculturais mais comuns foram: forma circular, borda lisa, aspecto homogêneo e ausência de aderência da colônia ao meio de cultivo (Figuras 1 a 4). Resultados semelhantes foram obtidos por Fonseca et al. (2003) e Zago (2003), que trabalharam com estirpes de pseudomonas fluorescentes, identificadas por meio de testes de assimilação de fontes de carbono e produção de enzimas. Esses autores observaram que a forma circular, a borda lisa e a ausência de aderência são características comuns às estirpes de Pseudomonas fluorescens e P. putida, assim como a fluorescência sob luz ultravioleta e a resistência aos antibióticos cloranfenicol e ampicilina adicionados ao meio de cultivo King B. Assim, os dados indicam que essas espécies são predominantes no presente trabalho. Ferreira et al. (2009) e Zago (2003) observaram que a forma e a borda da colônia não foram características relevantes na diferenciação dos grupos morfoculturais, ao passo que a elasticidade,

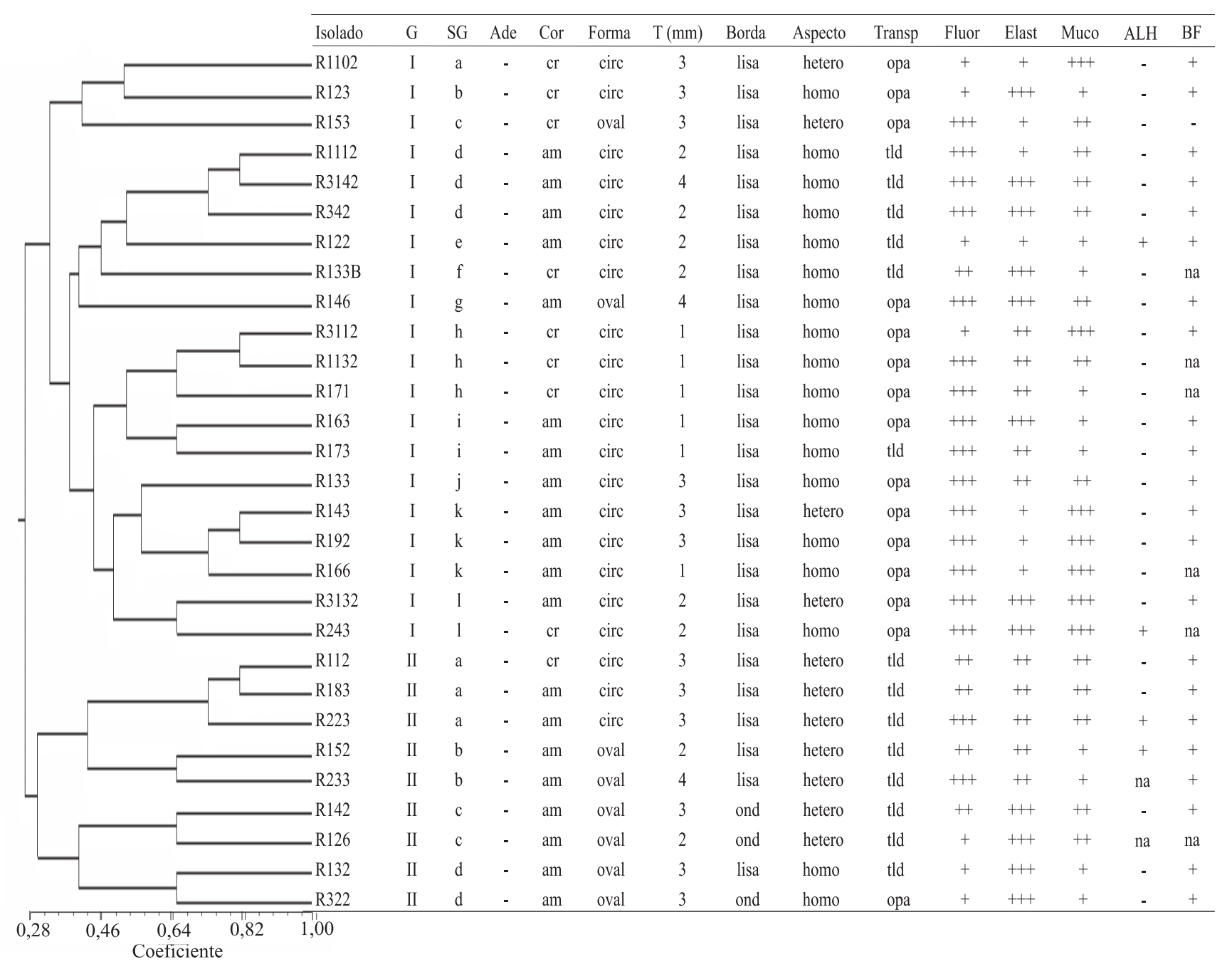

Figura 1. Caracterização morfocultural e agrupamento de rizobactérias fluorescentes, isoladas a partir da rizosfera de rúcula: Grupo (G); Subgrupo (SG); Cor - amarela (am) ou creme (cr); Forma - circular (circ) ou oval; Tamanho (T) - diâmetro em milímetros; Borda - lisa ou ondulada (ond); Aspecto do muco - homogêneo (homo) ou heterogêneo (hetero); Transparência (Transp) - translúcida (tld) ou opaca (opa); Fluorescência (fluor); Elasticidade (elast); Produção de muco (muco) - (+) baixa, $(++)$ média ou $(+++)$ alta; Aderência ao meio de cultura (Ade; Produção de acil lactonas homoserinas (ALH); e Biofilme (BF) - positivo (+) ou negativo (-); na, não avaliado; S/G, não agrupado. 


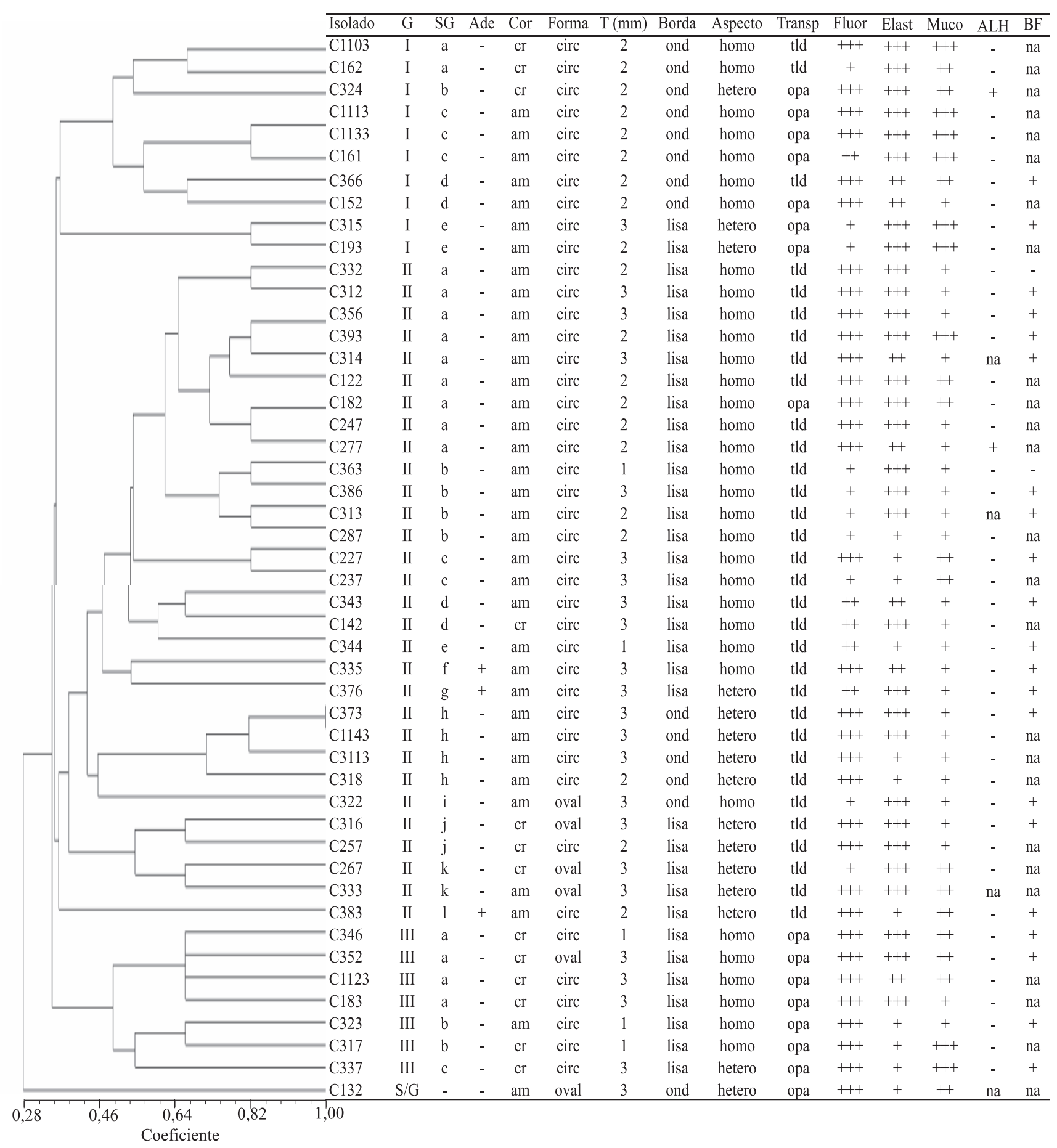

Figura 2. Caracterização morfocultural e agrupamento de rizobactérias fluorescentes, isoladas a partir da rizosfera de couve: Grupo (G); Subgrupo (SG); Cor - amarela (am) ou creme (cr); Forma - circular (circ) ou oval; Tamanho (T) - diâmetro em milímetros; Borda - lisa ou ondulada (ond); Aspecto do muco - homogêneo (homo) ou heterogêneo (hetero); Transparência (Transp) - translúcida (tld) ou opaca (opa); Fluorescência (fluor); Elasticidade (elast); Produção de muco (muco) - (+) baixa, $(++)$ média ou $(+++)$ alta; Aderência ao meio de cultura (Ade; Produção de acil lactonas homoserinas (ALH); e Biofilme (BF) - positivo (+) ou negativo (-); na, não avaliado; S/G, não agrupado. 


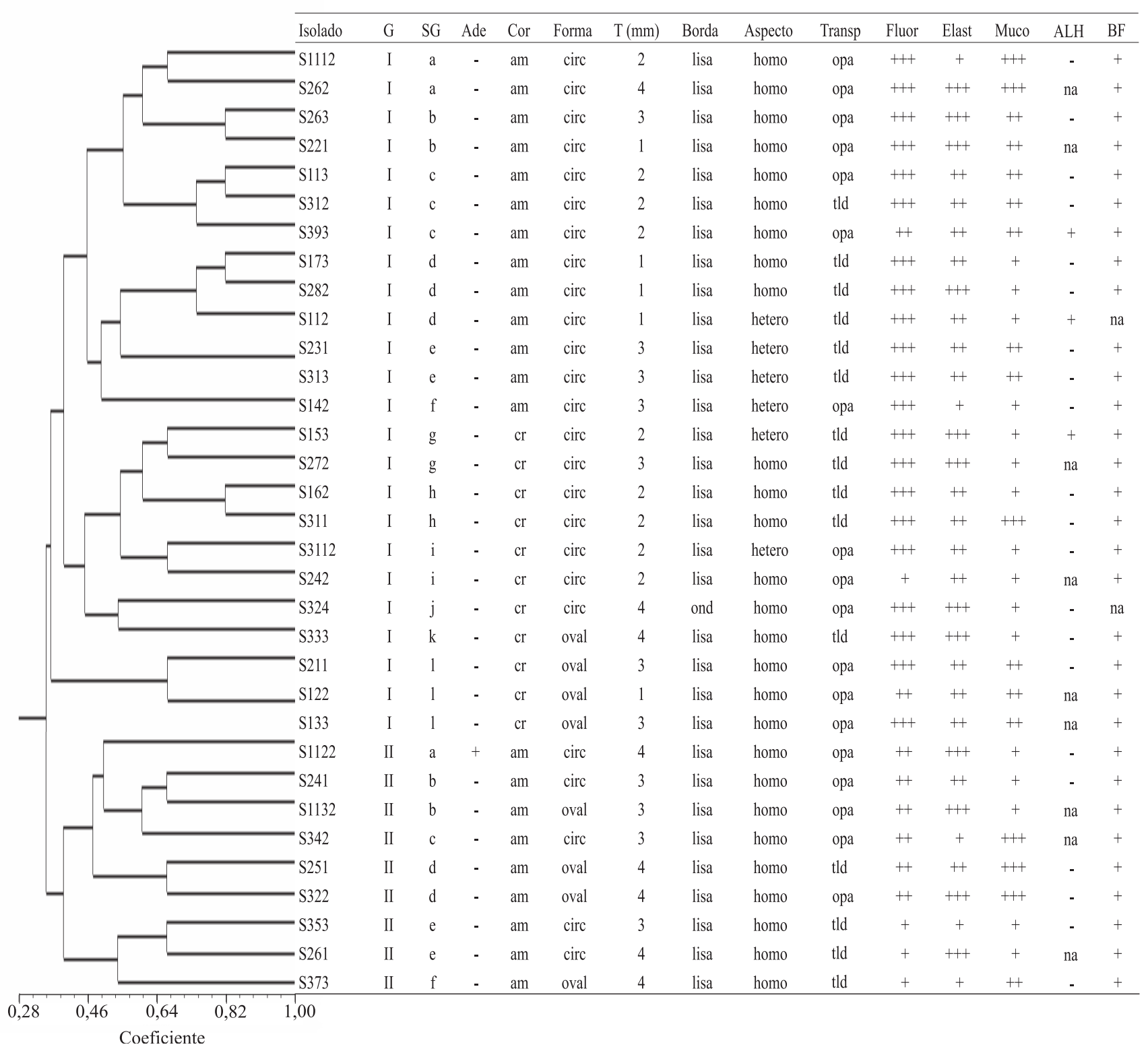

Figura 3. Caracterização morfocultural e agrupamento de rizobactérias fluorescentes, isoladas a partir da rizosfera de salsa: Grupo (G); Subgrupo (SG); Cor - amarela (am) ou creme (cr); Forma - circular (circ) ou oval; Tamanho (T) - diâmetro em milímetros; Borda - lisa ou ondulada (ond); Aspecto do muco - homogêneo (homo) ou heterogêneo (hetero); Transparência (Transp) - translúcida (tld) ou opaca (opa); Fluorescência (fluor); Elasticidade (elast); Produção de muco (muco) - (+) baixa, $(++)$ média ou $(+++)$ alta; Aderência ao meio de cultura (Ade; Produção de acil lactonas homoserinas (ALH); e Biofilme (BF) - positivo (+) ou negativo (-); na, não avaliado; S/G, não agrupado.

o tamanho, a fluorescência, a transparência e a cor foram relevantes. Neste trabalho, as bactérias fluorescentes foram mais abundantes na rizosfera de couve e menos abundantes na rizosfera de alface. Em contraste, Coelho et al. (2007) isolaram pseudomonas fluorescentes a partir de rúcula, alface e salsa e obtiveram o menor número de estirpes em salsa, e o maior número em alface.

As estirpes associadas à rúcula apresentaram no grupo I produção de muito muco, forma circular e homogeneidade das colônias, enquanto as estirpes do grupo II apresentaram de baixa a média produção de muco, forma oval e colônias heterogêneas em sua 


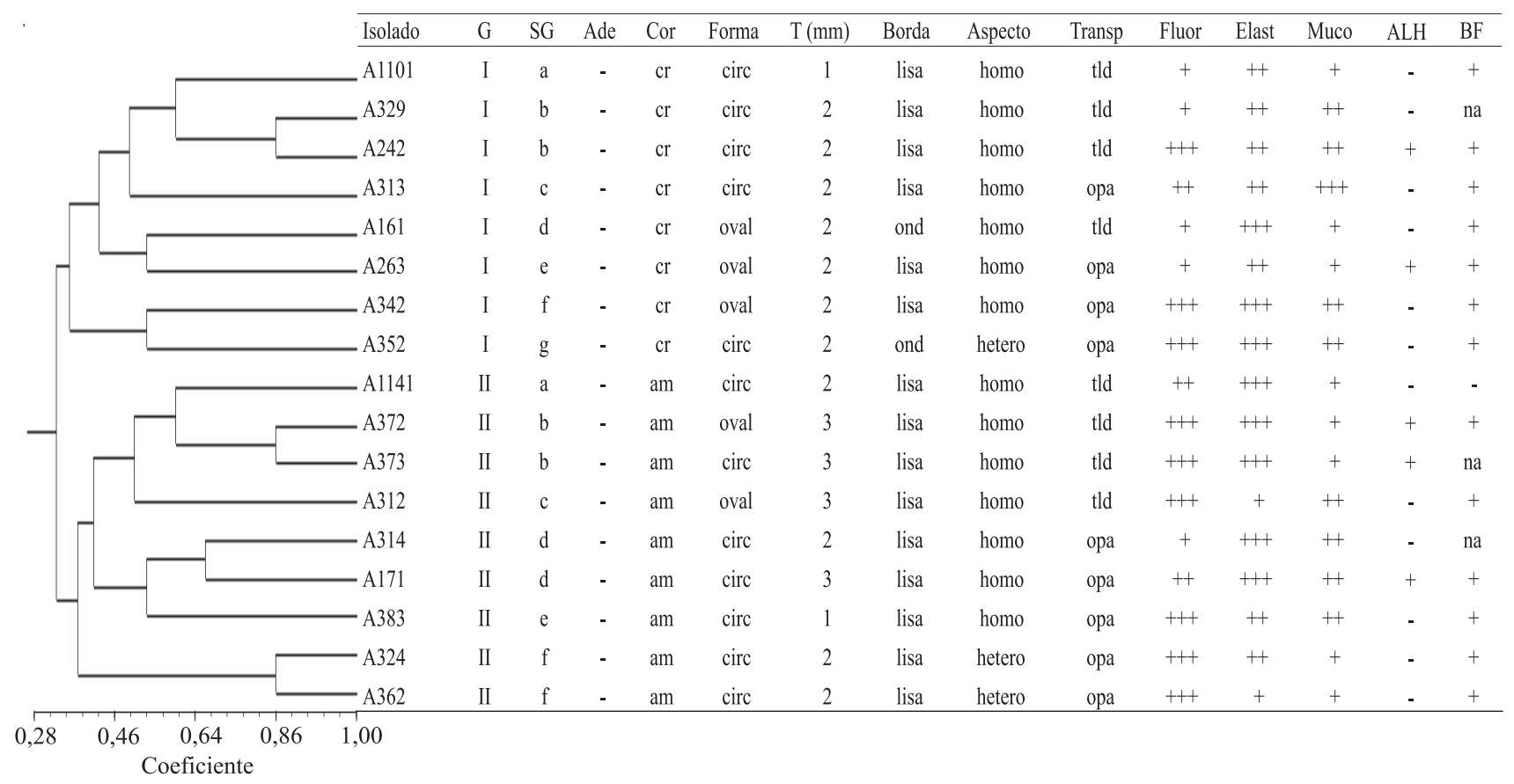

Figura 4. Caracterização morfocultural e agrupamento de rizobactérias fluorescentes, isoladas a partir da rizosfera de alface: Grupo (G); Subgrupo (SG); Cor - amarela (am) ou creme (cr); Forma - circular (circ) ou oval; Tamanho (T) - diâmetro em milímetros; Borda - lisa ou ondulada (ond); Aspecto do muco - homogêneo (homo) ou heterogêneo (hetero); Transparência (Transp) - translúcida (tld) ou opaca (opa); Fluorescência (fluor); Elasticidade (elast); Produção de muco (muco) - (+) baixa, $(++)$ média ou $(+++)$ alta; Aderência ao meio de cultura (Ade; Produção de acil lactonas homoserinas (ALH); e Biofilme (BF) - positivo (+) ou negativo (-); na, não avaliado; S/G, não agrupado.

maioria (Figura 1). As estirpes obtidas da rizosfera de couve apresentaram no grupo I, em sua maioria, tamanho igual a $2 \mathrm{~mm}$ e borda ondulada; no grupo II, prevaleceram colônias amarelas e translúcidas; no grupo III, prevaleceram colônias creme, opacas e com alta intensidade de fluorescência do muco; e uma estirpe não foi inserida nesses grupos e ficou num ramo separado (Figura 2). O grupo I, obtido de salsa apresentou alta fluorescência, e o grupo II baixa a média (Figura 3). Em alface, as estirpes do grupo I apresentaram coloração creme e elasticidade média, enquanto as do grupo II apresentaram, em sua maioria, cor amarela e alta elasticidade do muco (Figura 4).

A variabilidade encontrada nos valores dos índices de diversidade, calculados para os isolados obtidos de cada hortaliça, mostra que a rizosfera de couve apresentou maior riqueza de isolados (Tabela 1). Possivelmente, a maior riqueza e a diversidade das estirpes encontradas na rizosfera de couve refletem a pressão exercida pelos genótipos vegetais sobre a comunidade microbiana associada, por meio da quantidade e da qualidade dos exudatos radiculares que atuam de forma seletiva sobre as populações de bactérias fluorescentes (Mazzola et al., 2004). É importante ressaltar que o manejo do agroecossistema do qual foram coletadas as espécies olerícolas, e o estádio de desenvolvimento do vegetal, época do ano, assim como o esforço na obtenção das amostras e metodologia de isolamento são variáveis que podem contribuir com os resultados obtidos.

A partir dos grupos definidos com as características morfoculturais, 112 estirpes foram avaliadas quanto à produção de ALH. Pelos resultados observados, 14 (13\%) foram consideradas positivas, pela formação de halo azul no meio de cultura TY que continha a estirpe repórter A. tumefaciens NT1 (Tabela 2). Das estirpes testadas, obtidas da rizosfera de couve, duas $(4,5 \%)$ foram consideradas positivas contra três $(12,5 \%)$ obtidas de salsa, quatro $(14,8 \%)$ de rúcula e cinco $(29,4 \%)$ da rizosfera de alface. 
Tabela 2. Produção de N-acil lactonas homoserinas (ALH) e formação de biofilme por rizobactérias isoladas de hortaliças ${ }^{(1)}$.

\begin{tabular}{|c|c|c|c|c|c|c|c|}
\hline \multirow[t]{2}{*}{ Planta } & \multirow[t]{2}{*}{$\mathrm{N}$} & \multicolumn{2}{|c|}{$\mathrm{ALH}$} & \multicolumn{2}{|c|}{ Biofilme } & \multicolumn{2}{|c|}{ ALH e Biofilme } \\
\hline & & $\mathrm{nt}$ & + & $\mathrm{nt}$ & + & $\mathrm{nt}$ & + \\
\hline Couve & 48 & 44 & 2 & 23 & 21 & 21 & 0 \\
\hline Salsa & 33 & 24 & 3 & 31 & 31 & 22 & 2 \\
\hline Rúcula & 29 & 27 & 4 & 23 & 22 & 22 & 3 \\
\hline Alface & 17 & 17 & 5 & 14 & 13 & 14 & 4 \\
\hline Total & 127 & 112 & 14 & 91 & 87 & 79 & 9 \\
\hline
\end{tabular}

${ }^{(1)} \mathrm{N}$, número de estirpes; nt, número de estirpes testadas; $(+)$, resultado positivo.

Em um estudo realizado com 300 estirpes bacterianas, isoladas do solo e associadas a plantas, Vfselova et al. (2003) encontraram 17\% capazes de produzir ALH quando testadas com o sistema repórter A. tumefaciens. Kamilova et al. (2005) testaram cinco estirpes de rizobactérias promotoras de crescimento, com uso do sistema repórter $A$. tumefaciens, e apenas uma foi positiva. No trabalho de Sessitsch et al. (2005), foi recuperada uma estirpe de raízes de cebola que apresentou capacidade de biocontrole de Rhizoctonia solani e de promoção de crescimento de plantas de tomate, batata e videira. Quando testada com a bactéria repórter $A$. tumefaciens, esta estirpe foi positiva para a produção de ALH.

Pelo menos duas estirpes representantes de cada grupo morfocultural, no total de 91 estirpes, foram avaliadas quanto à capacidade de formar biofilme, das quais 87 (96\%) foram consideradas positivas (Tabela 2). Entre estas, 93\% obtidas da rizosfera de alface foram consideradas positivas, contra $91 \%$ de couve, $95 \%$ de rúcula e $100 \%$ de salsa. Das 79 estirpes avaliadas simultaneamente quanto à produção de ALH e formação de biofilme, apenas 9 (11\%) foram positivas e não mostraram relação entre estas duas características. O elevado percentual de bactérias produtoras de biofilme foi similar ao encontrado por Van Houdt et al. (2004), que também não verificaram relação entre a formação de biofilme e a produção de ALH. É possível que as estirpes avaliadas produzam outros autoindutores, que não foram detectados com a técnica adotada neste trabalho.

$\mathrm{Na}$ avaliação da capacidade de promover o crescimento de plantas de couve, quando as bactérias foram aplicadas com a suspensão de $10^{7} \mathrm{UFC} \mathrm{mL}^{-1}$, não houve diferença significativa entre as médias das massas de matéria fresca e seca das plantas inoculadas e a testemunha sem inoculação. A estirpe R142 promoveu o crescimento das raízes quando aplicada na dose de $10^{9} \mathrm{UFC}^{-1}$ (Tabela 3). A estirpe R142 foi eficiente em promover o crescimento de couve, pois as plantas com inoculação apresentaram aumento significativo de 55\% na massa de matéria seca das suas raízes, em relação à testemunha. Em um outro estudo, Sottero et al. (2006) realizaram experimento em casa de vegetação, com 64 rizobactérias, as quais nove ( $14 \%$ do total) promoveram aumento no número de folhas em alface, e quatro promoveram aumento de massa de matéria seca em raízes de plântulas de alface. Em experimento em casa de vegetação, Siddiqui \& Shaukat (2002) inocularam um consórcio de rizobactérias em tomateiros e constataram aumento da massa de matéria fresca da parte aérea nas plantas que receberam o inóculo, em comparação ao controle. Em experimento com mudas de abacaxi, Mello et al. (2002) inocularam diferentes consórcios de bactérias e obtiveram diferença significativa em relação à massa de matéria seca da parte aérea.

Tabela 3. Promoção de crescimento de plantas de couve, inoculadas com sete rizobactérias, nas doses de $10^{7}$ e $10^{9}$ UFC $\mathrm{mL}^{-1}$, aos dez dias após a semeadura(1).

\begin{tabular}{|c|c|c|c|}
\hline \multirow[t]{2}{*}{ Tratamento } & MFPA (g) & MSPA (g) & MSR (g) \\
\hline & \multicolumn{3}{|c|}{$10^{7} \mathrm{UFC} \mathrm{mL}^{-1}$} \\
\hline Controle & $2,77 \mathrm{~A}$ & $0,483 \mathrm{~A}$ & $0,220 \mathrm{~A}$ \\
\hline $\mathrm{C} 352$ & $3,11 \mathrm{~A}$ & $0,622 \mathrm{~A}$ & $0,218 \mathrm{~A}$ \\
\hline A161 & $3,61 \mathrm{~A}$ & $0,614 \mathrm{~A}$ & $0,278 \mathrm{~A}$ \\
\hline A242 & $3,49 \mathrm{~A}$ & $0,619 \mathrm{~A}$ & $0,232 \mathrm{~A}$ \\
\hline A1101 & $3,04 \mathrm{~A}$ & $0,580 \mathrm{~A}$ & $0,226 \mathrm{~A}$ \\
\hline A263 & $3,24 \mathrm{~A}$ & $0,593 \mathrm{~A}$ & $0,268 \mathrm{~A}$ \\
\hline $\mathrm{C} 122$ & $3,59 \mathrm{~A}$ & $0,612 \mathrm{~A}$ & $0,288 \mathrm{~A}$ \\
\hline \multirow[t]{2}{*}{ R142 } & $4,28 \mathrm{~A}$ & $0,784 \mathrm{~A}$ & $0,328 \mathrm{~A}$ \\
\hline & \multicolumn{3}{|c|}{$10^{9} \mathrm{UFC} \mathrm{mL}^{-1}$} \\
\hline Controle & $2,76 \mathrm{~A}$ & $0,486 \mathrm{~A}$ & $0,201 \mathrm{~A}$ \\
\hline C352 & $3,96 \mathrm{~A}$ & $0,564 \mathrm{~A}$ & $0,221 \mathrm{~A}$ \\
\hline A161 & $3,32 \mathrm{~A}$ & $0,650 \mathrm{~A}$ & $0,250 \mathrm{AB}$ \\
\hline A242 & $3,71 \mathrm{~A}$ & $0,578 \mathrm{~A}$ & $0,262 \mathrm{AB}$ \\
\hline A1101 & $3,78 \mathrm{~A}$ & $0,488 \mathrm{~A}$ & $0,271 \mathrm{AB}$ \\
\hline A263 & $3,84 \mathrm{~A}$ & $0,506 \mathrm{~A}$ & $0,287 \mathrm{AB}$ \\
\hline C122 & $3,54 \mathrm{~A}$ & $0,586 \mathrm{~A}$ & $0,291 \mathrm{AB}$ \\
\hline R142 & $4,85 \mathrm{~A}$ & $0,712 \mathrm{~A}$ & $0,441 \mathrm{~B}$ \\
\hline
\end{tabular}

Pesq. agropec. bras., Brasília, v.45, n.3, p.284-293, mar. 2010 


\section{Conclusões}

1. A coleção de rizobactérias obtida apresenta diversidade de morfologia cultural.

2. A produção de ALH e a formação de biofilme são características de 13 e $96 \%$ das estirpes avaliadas, respectivamente.

3. Não há relação entre a produção de ALH detectáveis e a formação de biofilme pelas estirpes avaliadas.

4. A estirpe R142 é eficiente na promoção de crescimento de couve e aumenta a massa de matéria

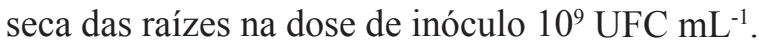

\section{Agradecimentos}

À Universidade Federal Rural do Rio de Janeiro, à Embrapa Agrobiologia, ao Conselho Nacional de Desenvolvimento Científico e Tecnológico, à Coordenação de Aperfeiçoamento de Pessoal de Nível Superior e à Fundação de Amparo à Pesquisa do Rio de Janeiro, pelo suporte técnico, científico e financeiro.

\section{Referências}

BERINGER, J.E.R. Factor transfer in Rhizobium leguminosarum. Journal of General Microbiology, v.84, p.188-198, 1974.

BODMAN, S.B. von; BAUER, W.D.; COPLIN, D.L. Quorum sensing in plant-pathogenic bacteria. Annual Review of Phytopathology, v.41, p.455-482, 2003.

CAMILLI, A.; BASSLER, B.L. Bacterial small-molecule signaling pathways. Science, v.311, p.1113-1116, 2006.

CHOUDHARY, D.K.; PRAKASH, A.; WRAY, V.; JOHRI, B.N. Insights of the fluorescent pseudomonads in plant growth regulation. Current Science, v.97, p.170-179, 2009.

COELHO, L.F.; FREITAS, S. dos S.; MELO, A.M.T. de; AMBROSANO, G.M.B. Interação de bactérias fluorescentes do gênero Pseudomonas e de Bacillus spp. com a rizosfera de diferentes plantas. Revista Brasileira de Ciência do Solo, v.31, p.1413-1420, 2007.

COMPANT, S.; CLÉMENT, C.; SESSITSCH, A. Plant growth-promoting bacteria in the rhizo- and endosphere of plants: their role, colonization, mechanisms involved and prospects for utilization. Soil Biology \& Biochemistry, v.42, p.669-678, 2010.

COOK, R.J. Tell me again what it is that you do. Annual Review of Phytopathology, v.45, p.1-23, 2007.

COSTERTON, J.W.; STEWART, P.S.; GREENBERG, E.P. Bacterial biofilms: a common cause of persistent infections. Science, v.284, p.1318-1322, 1999.
DANHORN, T.; FUQUA, C. Biofilm formation by plant-associated bacteria. Annual Review of Microbiology, v.61, p.401-422, 2007.

DECHO, A.W.; NORMAN, R.S.; VISSCHER, P.T. Quorum sensing in natural environments: emerging views from microbial mats. Trends in Microbiology, v.18, p.73-80, 2010.

FERREIRA, E.P. de B.; VOSS, M.; SANTOS, H.P. dos; DE-POLLI, H.; NEVES, M.C.P.; RUMJANEK, N.G. Diversidade de pseudomonas fluorescentes em diferentes sistemas de manejo do solo e rotação de culturas. Revista Brasileira de Ciências Agrárias, v.4, p.140-148, 2009.

FONSECA, M.C.C. Diversidade de Pseudomonas spp. fluorescentes num sistema integrado de produção agroecológica. 2003. 140p. Tese (Doutorado) - Universidade Federal Rural do Rio de Janeiro, Seropédica.

HAAS, D.; DÉFAGO, G. Biological control of soil-borne pathogens by fluorescent pseudomonads. Nature Reviews of Microbiology, v.3, p.307-319, 2005.

JUHAS, M.; EBERL, L.; TUMMLER, B. Quorum sensing: the power of cooperation in the world of Pseudomonas. Environmental Microbiology, v.7, p.459-471, 2005.

KAMILOVA, F.; VALIDOV, S.; AZAROVA, T.; MULDERS, I.; LUGTENBERG, B. Enrichment for enhance competitive plant root tip colonizers selects for a new class of biocontrol bacteria. Environmental Microbiology, v.7, p.1809-1817, 2005.

MAGURRAN, A.E. Ecological diversity and its measurement. New Jersey: Princeton University Press, 1988. 179p.

MAZZOLA, M.; FUNNELL, D.L.; RAAIJMAKERS, J.M. Wheat cultivar-specific selection of 2,4-diacetylphloroglucinol-producing fluorescent Pseudomonas species from resident soil populations. Microbial Ecology, v.48, p.338-348, 2004.

MELLO, M.R.F. de; MARIANO, R.L.R.; MENEZES, M.; CÂMARA, T.R.; ASSIS, S.M.P. Seleção de bactérias e métodos de bacterização para promoção de crescimento em mudas de abacaxizeiro micropropagadas. Summa Phytopathologica, v.28, p.222-228, 2002.

RUMJANEK, N.G.; FONSECA, M.C.C. da; XAVIER, G.R. Quorum sensing em sistemas agrícolas. Revista Biotecnologia, Ciência \& Desenvolvimento, v.33, p.35-50, 2004.

SESSITSCH, A.; COENYE, T.; STURZ, A.V.; VANDAMME, P.; BARKA, E.A.; SALLES, J.F.; VAN ELSAS, J.D.; FAURE, D.; REITER, B.; GLICK, B.R.; WANG-PRUSKI, G.; NOWAK, J. Burkholderia phytofirmans sp. nov., a novel plant-associated bacterium with plant-beneficial properties. International Journal of Systematic and Evolutionary Microbiology, v.55, p.1187-1192, 2005.

SIDDIQUI, I.A.; SHAUKAT, S.S. Mixtures of plant disease suppressive bacteria enhance biological control of multiple tomato pathogens. Biology and Fertility of Soils, v.36, p.260-268, 2002.

SOTTERO, A.N.; FREITAS, S. dos S.; MELO, A.M.T. de; TRANI, P.E. Rizobactérias e alface: colonização rizosférica, 
promoção de crescimento e controle biológico. Revista Brasileira de Ciência do Solo, v.30, p.225-234, 2006.

VAN HOUDT, R.; AERTSEN, A.; JANSEN, A.; QUINTANA, A.L.; MICHIELS, C.W. Biofilm formation and cell-to-cell signalling in Gram-negative bactéria isolated from a food processing environment. Journal of Applied Microbiology, v.96, p.177-184, 2004.

VESELOVA, M.A. Quorum sensing regulation in Pseudomonas. Russian Journal of Genetics, v.46, p.129-137, 2010.
VFSELOVA, M.; KHOLMECKAYA, M.; KLEIN, S.; VORONINA, E.; LIPASOVA, V.; METLITSKAYA, A.; MAYATSKAYA, A.; LOBANOK, E.; KHMEL, I.; CHERNIN, L. Production of $\mathrm{N}$-acylhomoserine lactone signal molecules by gram-negative soil-borne and plant-associated bacteria. Folia Microbiologica, v.48, p.794-798, 2003.

ZAGO, V.C.P. Efeito de olerícolas sob manejo orgânico e diferentes adubos na diversidade das populações de Pseudomonas spp. fluorescentes. 2003. 103p. Tese (Doutorado) Universidade Federal Rural do Rio de Janeiro, Seropédica.

Recebido em 20 de agosto de 2009 e aprovado em 29 de janeiro de 2010 